\title{
Therapy for Primary Vulvar Carcinoma
}

\section{Therapie des primären Vulvakarzinoms}

Authors

Affiliation
D. Herr, I. Juhasz-Boess, E. F. Solomayer

Frauenklinik, Universitätsklinikum Homburg/Saar, Homburg, Saar

Key words
vulva
cancer
therapy
Schlüsselwörter
Vulva
Karzinom
Therapie

Deutschsprachige Zusatzinformationen online abrufbar unter: www.thieme-connect.de/ ejournals/toc/gebfra

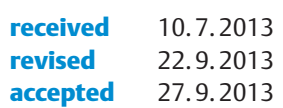

Bibliography

DOI http://dx.doi.org/

10.1055/s-0033-1360145

Geburtsh Frauenheilk 2014; 74 :

271-275 @ Georg Thieme

Verlag KG Stuttgart · New York . ISSN 0016-5751

\section{Correspondence}

\section{Dr. Daniel Herr, PD}

Universitätsklinikum Homburg/

Saar

Frauenklinik

Kirrbergerstraße 100

66424 Homburg/Saar

daherr@gmx.de

\section{Abstract \\ $\nabla$}

The rather rare vulvar cancer is almost always a squamous cell carcinoma that mostly develops from an underlying VIN or HPV infection. In addition, lichen sclerosus et atrophicans, immune deficiency, nicotine abuse or anogenital intraepithelial neoplasias may play a role in the pathogenesis. Surgical therapy aims at an R0 resection in the sense of a complete vulvectomy or a radical local excision with, if necessary, plastic reconstruction. Also, the vulvar field resection with consideration of the compartment model has been discussed. Besides the classic inguinofemoral lymphadenectomy, in selected cases of vulvar cancer sentinel biopsies are performed by experienced surgeons in the larger centres. In contrast, systemic therapy plays only a subordinate role; in isolated cases down-staging by means of neoadjuvant chemotherapy may be useful. However, there is at present no indication for adjuvant chemotherapy. Neoadjuvant radiochemotherapy is also not to be recommended on account of its unfavourable ratio of efficacy to side effects. On the other hand adjuvant radiotherapy is indicated in cases of positive inguinal lymph nodes. According to the current data the indication should be made generously in such cases.

\section{Introduction \\ $\nabla$}

With an incidence of $4 \%$ of all malignancies of the female genital tract, vulvar carcinoma is rather a rare form of cancer. From the histopathological point of view it is usually a squamous cell carcinoma, but adenocarcinomas, melanomas and carcinomas of the Bartholin glands may also occur in

\section{Zusammenfassung \\ $\nabla$}

Das eher seltene Vulvakarzinom ist fast immer ein Plattenepithelkarzinom, das meist auf dem Boden einer vulvären intraepithelialen Neoplasie (VIN) oder einer HPV-Infektion entsteht. Daneben sind auch der Lichen sclerosus et atrophicans, eine Immundefizienz, Nikotinabusus oder anogenitale intraepitheliale Neoplasien an der Pathogenese beteiligt. Die operative Therapie zielt auf eine R0Resektion im Sinne einer kompletten Vulvektomie oder einer radikalen lokalen Exzision ggf. mit plastischer Rekonstruktion. Daneben wird zunehmend auch die Vulvafeldresektion unter Berücksichtigung des Kompartment-Modells diskutiert. Neben der klassischen inguinofemoralen Lymphonodektomie wird auch beim Vulvakarzinom die Sentinel-Biopsie in größeren Zentren und ausgewählten Situationen von erfahrenen Operateuren durchgeführt. Die Systemtherapie spielt dagegen eine nur untergeordnete Rolle; in Einzelfällen kann ein Downstaging durch eine neoadjuvante Chemotherapie sinnvoll sein. Für eine adjuvante Chemotherapie gibt es derzeit keine Indikation. Ebenfalls sollte eine neoadjuvante Radiochemotherapie aufgrund der ungünstigen Ratio an Effektivität und Nebenwirkungen vermieden werden. Im Gegensatz dazu ist eine adjuvante Bestrahlung aber bei positiven inguinalen Lymphknoten indiziert. Hierzu sollte die Indikation nach aktuellen Daten großzügig gestellt werden.

the vulvar region. Current projections for Germany assume about 3400-4000 new cases of vulvar cancer per year (A. Katalinic/U. Gerdemann: current statistics on vulvar cancer in Germany March 2011, cancer register [Aktuelle Zahlen zum Vulvakarzinom in Deutschland März 2011, Krebsregister]). These figures reflect the increasing occurrence of vulvar cancer over the past 


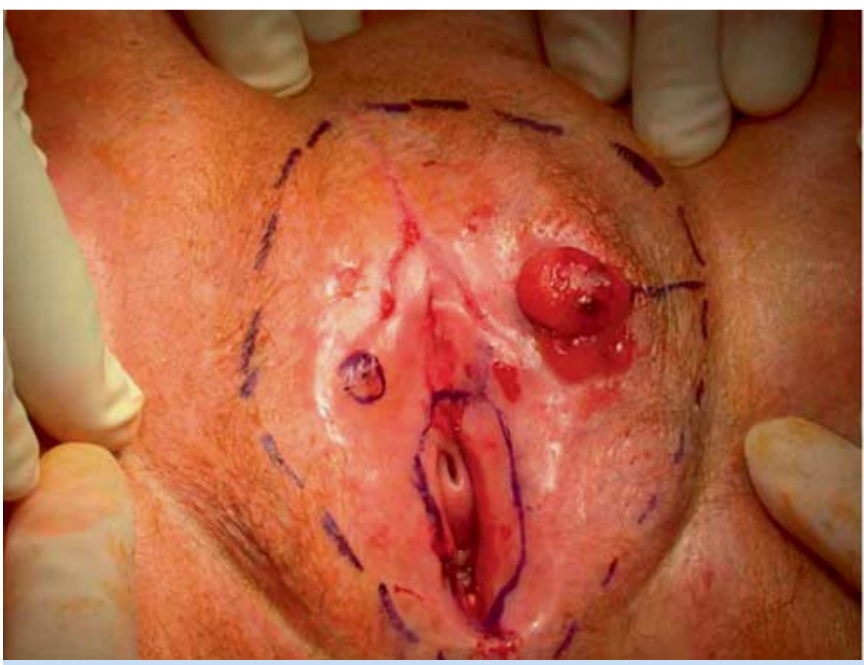

Fig. 1 Advanced vulvar cancer before and after radical vulvectomy. On the left one can see the preoperative situation with multifocal tumour disease

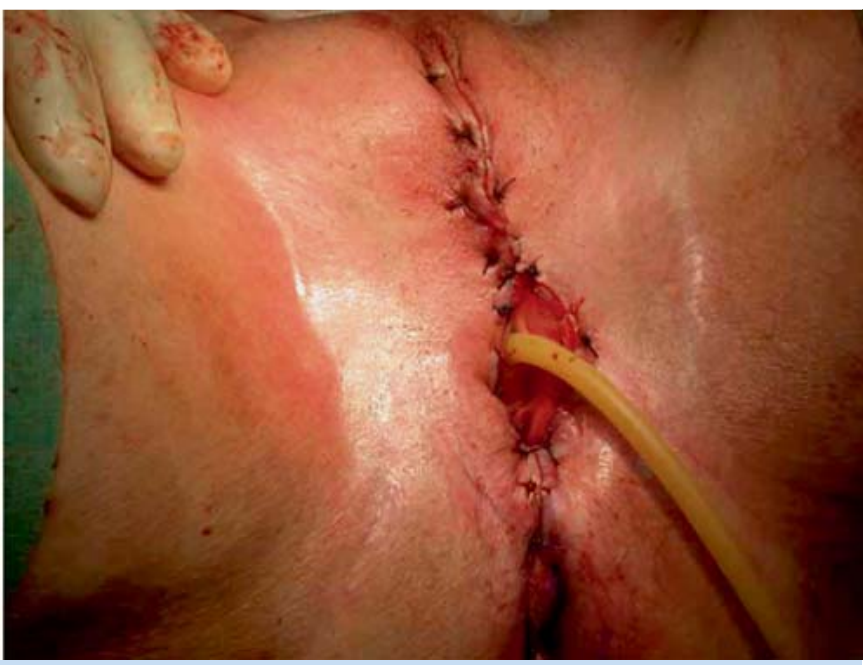

with the resection shape including removal of the clitoris. On the right one can see the postoperative result after placement of a bladder catheter. years [1-4]. In the past, especially women aged 70 years or more were afflicted, but in recent years the proportion of afflicted younger women has increased markedly. This is probably related to the fact that $40-60 \%$ of vulvar cancer and up to $90 \%$ of VIN cases are associated with HPV $[1,2,5]$. Among the vulvar cancers the following HPV subtypes in order of frequency have been identified: HPV subtypes 16, 33, 6, 18 and 31, with HPV 16 having the largest proportion of over 50\% [6]. Other factors that may be involved in the development of vulvar cancer are, especially for older patients, lichen sclerosus et atrophicans, inherited or acquired immune deficiency, nicotine abuse or anogenital intraepithelial neoplasias. Thus, in the past few years a bimodal age distribution has become increasingly apparent: a first peak at 45 to 50 years and a second peak at 70 to 75 years of age [7]. Staging is done in accordance with the FIGO and the TNM classifications. Decisive factors are the surgical findings and results of the histopathological analysis of surgical specimens.

\section{Operative Therapy}

$\nabla$

\section{Stage-adapted therapy}

In principle, in the primary situation of surgical therapy for vulvar cancer, attempts should always be made to achieve an R0 resection. Only in exceptional cases such as, for example, an unacceptable risk of narcosis or in a palliative situation is primary radio(chemo)therapy indicated. For decades the standard surgical therapy consisted of an en-bloc resection of the vulva with bilateral inguinal lymphadenectomy (LNE). Because of the mutilating nature of this procedure and the numerous postoperative complications such wound-healing disorders (especially in obese female patients with diabetes), disturbances of bladder function, vaginal stenosis and chronic pain, a paradigm shift in favour of reduced surgical radicality has taken place during the past 10 to 15 years. Accordingly in most large centres the traditional enbloc resection has been replaced by the so-called triple incision. Besides the vulvectomy dissection-shaped incision ( $\bullet$ Fig. 1), two separate incisions in the groin area are made for the inguinal LNE. This procedure, which has in the meantime advanced to be the standard, exhibits a markedly lower rate of wound-healing disor- ders. Since this procedure also leads to loss of the clitoris, in the sense of a further reduction in the radicality, at least in early tumour stages the triple incision is supplemented or, respectively, substituted by a radical local excision. In this procedure the tumour is resected macroscopically on all sides into healthy tissue. When this resection is widely performed it is also referred to as a partial vulvectomy. In a meta-analysis of data from 11 studies involving a total of 530 patients with T1 vulvar cancer, comparable rates of local recurrences were found for patients who underwent a radical local excision and those who, respectively, underwent a radical vulvectomy. The cancer-related mortality rates were also similar (0.6 vs. $0.5 \%$ ) (7.2 vs. $6.3 \%$ ) [8]. Depending on the localisation of the tumour, the radical local excision is classified as a partial anterior or a posterior vulvectomy or a hemivulvectomy. Although the radical local excision is now generally accepted it should be noted that only limited data are available on the progression-free or overall survival.

In clinical routine the following stage-adapted procedures are now established:

- T1a: radical local excision

- T1b: radical local excision, when in a median position with ipsi- or bilateral inguinal LNE

- T2: radical local excision with bilateral inguinal LNE and, if necessary, with pelvic LNE

- T3/4: radical vulvectomy with bilateral inguinal LNE and, if necessary, with pelvic LNE or also anterior/posterior or total exenteration

Independent of the surgical procedure, intraoperative macroscopic safety margins of $10 \mathrm{~mm}$ are recommended. In this way it is ensured that the $8-\mathrm{mm}$ margins required by histology are still detectable even after artefacts from shrinking [9].

\section{Compartment model}

Similar to colon and cervix cancer, the compartment model is also under discussion for vulvar cancer. This model is based on the following theory.

Malignancies spread over a relatively long period of time within the tissue compartments predetermined by embryonic development. In spite of their close spatial relationships, neighbouring compartments are at first not infiltrated by the tumour. The com- 

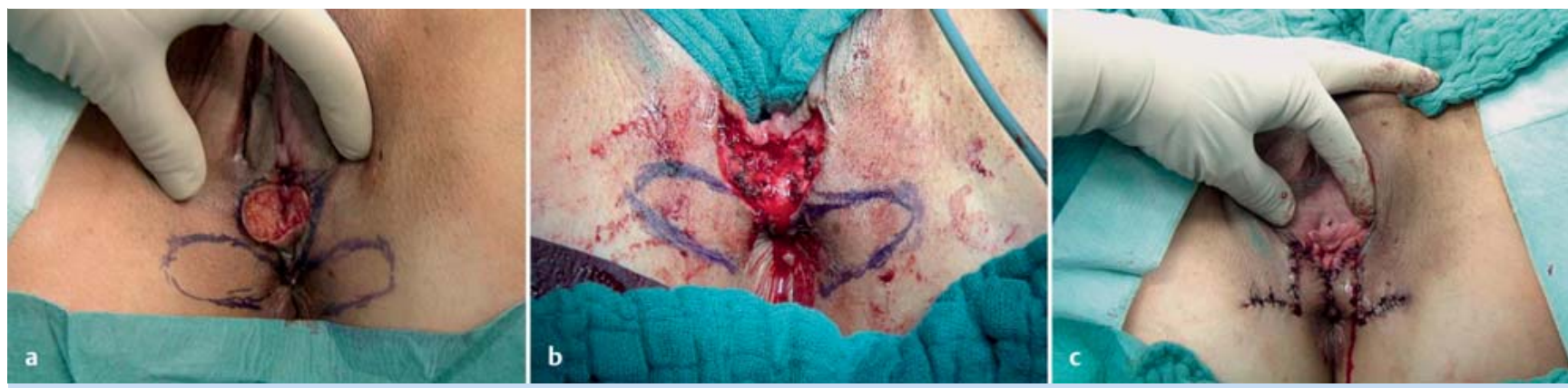

Fig. 2a to c Posterior vulvar field resection with reconstruction: a vulvar cancer in the region of the posterior commissure after marking the incision lines. Laterally the respective flaps to be rotated are marked (Limberg flaps). b After resection of the posterior vulvar field. c Postoperative result after plastic reconstruction by rotation of the flaps. plete removal of the respective morphogenetic unit or a segment of this compartment with minimal surgical trauma and retention of the neighbouring structures of different embryonic origin can result in an increased surgical radicality with reduced mortality. In cases of vulvar cancer three compartments can be distinguished:

The deep compartment, that originates embryonically from the genital tubercle and from which the clitoris, bulbus and vestibulum develop, the superficial compartment originating from the urogenital folds which differentiate into the glans clitoridis, the labia minor and the inner sides of the labia major, and the lateral compartment, the origin of the outer sides of the labia major. Consideration of these embryonically predefined structures during the surgical or therapeutic planning in the sense of a vulvar field resection offers an enormous potential for increasing the surgical-oncological radicality and efficacy. It has been shown prospectively that, in about $50 \%$ of the patients in tumour stage T1-3, who underwent such a vulvar field resection with up to 50 months follow-up observation and 5\% local morbidity, not one single local recurrence developed (with radical vulvectomy over all stages the rate is 25-35\%) [10]. However, since the available data are limited and these results are all from a single centre, this procedure is not yet established as a standard and must still prove its value in the future.

The surgical procedure in the framework of a posterior vulvar field resection with reconstruction is shown in 0 Fig. 2 .

\section{Relevance of (Sentinel) Lymphadenectomy}

In principle the lymph outflow of the vulva proceeds through the lymph nodes of the groin, which include both the superficial inguinal and the deeper femoral lymph nodes. The probability of lymphatic metastatic spread in this region does not depend on the tumour stage or, respectively, the visible tumour size. Solely for the infiltration depth has a positive correlation with positive groin lymph nodes been detected in numerous studies [11-13]. Thus, at an infiltration depth of $>1 \mathrm{~mm}$ (pT1b) the groin lymph nodes should be removed. This should be done in the sense of a bilateral systematic inguinofemoral lymphadenectomy, since removal of merely the superficial inguinal lymph nodes carries a markedly higher risk of a prognostically very unfavourable groin recurrence. In such cases the removal of at least 6 lymph nodes of each type is recommended $[14,15]$. Only for very small cancers with a far lateral localisation and free ipsilateral lymph nodes is it possible to omit the contralateral lymphadenectomy, since a very low rate $(<0.5 \%)$ of positive lymph nodes can be assumed [16-19].

\section{Relevance of the pelvic lymphadenectomy}

Lymph drainage of the vulva occurs almost exclusively via the inguinofemoral lymph nodes. Only in cases of extensive disease is lymphatic metastatic spread via the femoral drainage pathways through to the external iliac veins and arteries in the direction of the pelvic lymph nodes to be expected. A communication via the plexus venosus vaginalis with the internal lymph nodes as is known in cases of vaginal carcinoma has not been described for vulvar cancer. Thus, with an incidence of $2 \%$ pelvic lymph node metastases are rather rare in early vulvar cancer of stage T1/T2 [20-22].

This results in a possible indication for pelvic lymphadenectomy only in cases with confirmed lymphogenic metastatic spread in the groin. Accordingly pelvic lymphadenectomy is recommended in cases with 3 or more positive unilateral groin lymph nodes, with capsule rupture, or with macrometastasis $>10 \mathrm{~mm}$.

\section{Sentinel lymphadenectomy}

In principle, the concept of sentinel lymphadenectomy seems to be attractive also for vulvar cancer on account of the highly relevant postoperative morbidity of a systematic inguinofemoral lymphadenectomy. Unfortunately, however, groin recurrences after sentinel lymphadenectomy alone have been reported in numerous publications [23-26]. Even so, the sentinel procedure is justified in tumour stages T1 and T2 according to the data of Zee et al. [27]. In the framework of this work involving over 400 patients the authors demonstrated a marked in morbidity with a $2.3 \%$ rate of groin recurrence. Since in the meantime also prospective data on this topic have become available [28], sentinel lymphadenectomy can be considered as an alternative to systematic bilateral inguinofemoral lymphadenectomy in cases of vulvar cancer when the patients are informed adequately.

\section{Systemic Therapy \\ $\nabla$}

On the whole, systemic therapy for primary vulvar cancer in the form of adjuvant or neoadjuvant chemotherapy has not had a history of success. Even so there have been isolated publications in the past few years concerning, above all, cisplatin, 5-FU or bleo- 
mycin that may possibly redefine the role of systemic therapy for vulvar cancer.

In the adjuvant situation it has been shown that a cisplatin monotherapy subsequent to surgical treatment may in individual cases with afflicted groin lymph nodes be a reasonable option also with regard to survival [29]. However, due to the small number of cases, the results of further studies must certainly be awaited. Neoadjuvant therapy is an interesting therapeutic concept, especially for advanced or, respectively, inoperable vulvar cancer [3032]. The first objective here is a reduction of tumour size, which can then facilitate a subsequent local therapy or even change a primarily inoperable situation into a resectable finding, in such a case exenteration can be avoided and the patient's quality of life improved. In addition, neoadjuvant chemotherapy can treat possibly present micrometastases and thus reduce the chances for distant metastatic spread [33-35]. However, due to the small number of patients, the use of neoadjuvant chemotherapy for vulvar cancer is still restricted to individual cases and further studies are needed.

\section{Radiation}

\section{Primary radiochemotherapy}

In cases of local advanced vulvar cancer a primary radiochemotherapy, usually with cisplatin, 5-FU or also mitomycin C, may be employed. This may be indicated in patients with inoperable findings or to avoid a radical surgical intervention (exenteration) [36]. In spite of the high rate of clinical remissions of 46-91\% [3741], residual tumours are frequently found on histopathology [40-42]. Thus, surgical sanitation should also follow directly after the primary radiochemotherapy; thus it is better in this context to refer to it as a neoadjuvant radiochemotherapy. All of the studies, although very heterogeneous with respect to study population and treatment schemes, have in common reported pronounced skin toxicity. Furthermore, randomised studies have shown no benefit in comparison with primary operations with regard to recurrence-free and overall survival [43], but they did reveal markedly higher rates of complications. Under consideration of the facts that the surgical procedure is more difficult after a prior radiation and that the option for radiation is still open in the case of a recurrence, a neoadjuvant radiochemotherapy remains reserved for exceptional cases.

\section{Adjuvant radiation}

Together with macrometastases $>10 \mathrm{~mm}$ and a capsule rupture in the region of the inguinal lymph nodes and since the GOG study of Homesley et al. 1986, irradiation of the inguinal and pelvic lymph drainage pathways or a pelvic lymphadenectomy in combination with an inguinal radiotherapy are recommended in cases with 3 or more afflicted inguinal lymph nodes [44]. This procedure was the gold standard for a long time; however, since the ASCO 2012 and the results of the as yet largest multicentre study on nodal-positive vulvar cancer presented there, the indication for adjuvant radiation of the lymph drainage pathways has been expanded. In the AGO Care 1 Study a benefit of adjuvant radiation was observed independent of the number of positive lymph nodes. For this reason radiotherapy is now being discussed already for patients with just one afflicted inguinal lymph node. In addition, for $\mathrm{R} 1$ resection or marginal R0 resection without further surgical options, a subsequent radiation of the tumour bed should be carried out [45].

\section{Perspectives and Conclusion}

$\nabla$

The management of vulvar cancer requires an interdisciplinary therapy in which surgery and radiotherapy play important roles. The precise significance of neoadjuvant chemotherapy needs to be clarified in further studies. Adjuvant radiation of the groin in the case of only one positive inguinal lymph node will certainly be a topic for future discussion.

\section{Acknowledgements}

We are grateful to Dr. Wolfgang Schmitt for provision of the graphic material.

\section{Conflict of Interest}

\section{$\nabla$}

None.

\section{References}

1 Hampl M, Deckers-Figiel S, Hampl JA et al. New aspects of vulvar cancer: changes in localization and age of onset. Gynecol Oncol 2008; 109: 340-345

2 Judson PL, Habermann EB, Baxter NN et al. Trends in the incidence of invasive and in situ vulvar carcinoma. Obstet Gynecol 2006; 107: 1018-1022

3 Maclean $A B$. Vulval cancer: prevention and screening. Best Pract Res Clin Obstet Gynaecol 2006; 20: 379-395

4 Beckmann MW, Bader W, Bechtold I et al. [Financing and financial problems of care and structures in the field of gynaecology and obstetrics in the year 2011 - DRG system and inpatient care with urogynaecology and benign and malign gynaecological surgery, second paper of the financing commission of the DGGG e.V. - Part II]. Geburtsh Frauenheilk 2011; 71: 497-510

5 Joura EA, Losch A, Haider-Angeler MG et al. Trends in vulvar neoplasia. Increasing incidence of vulvar intraepithelial neoplasia and squamous cell carcinoma of the vulva in young women. J Reprod Med 2000; 45: 613-615

6 Insinga RP, Liaw KL, Johnson LG et al. A systematic review of the prevalence and attribution of human papillomavirus types among cervical, vaginal, and vulvar precancers and cancers in the United States. Cancer Epidemiol Biomarkers Prev 2008; 17: 1611-1622

7 Jones RW, Baranyai J, Stables S. Trends in squamous cell carcinoma of the vulva: the influence of vulvar intraepithelial neoplasia. Obstet Gynecol 1997; 90: 448-452

8 Hacker NF. Radical resection of vulvar malignancies: a paradigm shift in surgical approaches. Curr Opin Obstet Gynecol 1999; 11: 61-64

9 Heaps JM, Fu YS, Montz FJ et al. Surgical-pathologic variables predictive of local recurrence in squamous cell carcinoma of the vulva. Gynecol Oncol 1990; 38: 309-314

10 Hockel M, Schmidt K, Bornmann K et al. Vulvar field resection: novel approach to the surgical treatment of vulvar cancer based on ontogenetic anatomy. Gynecol Oncol 2010; 119: 106-113

11 Hacker NF, Berek JS, Lagasse LD et al. Management of regional lymph nodes and their prognostic influence in vulvar cancer. Obstet Gynecol 1983; 61: 408-412

12 Iversen T, Aalders JG, Christensen A et al. Squamous cell carcinoma of the vulva: a review of 424 patients, 1956-1974. Gynecol Oncol 1980; 9: 271-279

13 Kramer F, Hertel $H$, Hillemanns $P$ et al. Use of the sentinel lymph node technique compared to complete inguino-femoral lymph node removal in patients with invasive vulvar cancer in Germany. Geburtsh Frauenheilk 2013; 73: 142-147

14 Podratz KC, Symmonds RE, Taylor WF. Carcinoma of the vulva: analysis of treatment failures. Am J Obstet Gynecol 1982; 143: 340-351

15 Raspagliesi F, Ditto A, Fontanelli $R$ et al. False-negative sentinel node in patients with vulvar cancer: a case study. Int J Gynecol Cancer 2003; 13: $361-363$ 
16 Coleman RL, Ali S, Levenback CF et al. Is bilateral lymphadenectomy for midline squamous carcinoma of the vulva always necessary? An analysis from Gynecologic Oncology Group (GOG) 173. Gynecol Oncol 2013; 128: 155-159

17 Curry SL, Wharton JT, Rutledge F. Positive lymph nodes in vulvar squamous carcinoma. Gynecol Oncol 1980; 9: 63-67

18 Green jr. TH. Carcinoma of the vulva. A reassessment. Obstet Gynecol 1978; 52: 462-469

19 Wharton JT, Gallager S, Rutledge FN. Microinvasive carcinoma of the vulva. Am J Obstet Gynecol 1974; 118: 159-162

20 Klemm P, Marnitz S, Kohler C et al. Clinical implication of laparoscopic pelvic lymphadenectomy in patients with vulvar cancer and positive groin nodes. Gynecol Oncol 2005; 99: 101-105

21 Magrina JF, Webb MJ, Gaffey TA et al. Stage I squamous cell cancer of the vulva. Am J Obstet Gynecol 1979; 134: 453-459

22 van der Velden J, van Lindert AC, Lammes FB et al. Extracapsular growth of lymph node metastases in squamous cell carcinoma of the vulva. The impact on recurrence and survival. Cancer 1995; 75: 2885-2890

23 Boran N, Kayikcioglu F, Kir M. Sentinel lymph node procedure in early vulvar cancer. Gynecol Oncol 2003; 90: 492-493

24 Decesare SL, Fiorica JV, Roberts WS et al. A pilot study utilizing intraoperative lymphoscintigraphy for identification of the sentinel lymph nodes in vulvar cancer. Gynecol Oncol 1997; 66: 425-428

25 de Hullu JA, Hollema H, Piers DA et al. Sentinel lymph node procedure is highly accurate in squamous cell carcinoma of the vulva. J Clin Oncol 2000; 18: 2811-2816

26 Fons $G$, ter Rahe B, Sloof $G$ et al. Failure in the detection of the sentinel lymph node with a combined technique of radioactive tracer and blue dye in a patient with cancer of the vulva and a single positive lymph node. Gynecol Oncol 2004; 92: 981-984

27 Van der Zee AG, Oonk MH, De Hullu JA et al. Sentinel node dissection is safe in the treatment of early-stage vulvar cancer. J Clin Oncol 2008; 26: 884-889

28 Levenback CF, Ali S, Coleman RL et al. Lymphatic mapping and sentinel lymph node biopsy in women with squamous cell carcinoma of the vulva: a gynecologic oncology group study. J Clin Oncol 2012; 30 3786-3791

29 Bellati F, Angioli R, Manci $N$ et al. Single agent cisplatin chemotherapy in surgically resected vulvar cancer patients with multiple inguinal lymph node metastases. Gynecol Oncol 2005; 96: 227-231

30 Shimizu Y, Hasumi K, Masubuchi K. Effective chemotherapy consisting of bleomycin, vincristine, mitomycin C, and cisplatin (BOMP) for a patient with inoperable vulvar cancer. Gynecol Oncol 1990; 36: 423-427

31 Durrant KR, Mangioni C, Lacave AJ et al. Bleomycin, methotrexate, and CCNU in advanced inoperable squamous cell carcinoma of the vulva: a phase II study of the EORTC Gynaecological Cancer Cooperative Group (GCCG). Gynecol Oncol 1990; 37: 359-362
32 Wagenaar HC, Colombo N, Vergote I et al. Bleomycin, methotrexate, and CCNU in locally advanced or recurrent, inoperable, squamous-cell carcinoma of the vulva: an EORTC Gynaecological Cancer Cooperative Group Study. European Organization for Research and Treatment of Cancer. Gynecol Oncol 2001; 81: 348-354

33 Benedetti-Panici P, Greggi S, Scambia G et al. Cisplatin (P), bleomycin (B), and methotrexate (M) preoperative chemotherapy in locally advanced vulvar carcinoma. Gynecol Oncol 1993; 50: 49-53

34 Geisler JP, Manahan KJ, Buller RE. Neoadjuvant chemotherapy in vulvar cancer: avoiding primary exenteration. Gynecol Oncol 2006; 100: $53-$ 57

35 Domingues AP, Mota F, Durao $M$ et al. Neoadjuvant chemotherapy in advanced vulvar cancer. Int J Gynecol Cancer 2010; 20: 294-298

36 Boronow RC, Hickman BT, Reagan MT et al. Combined therapy as an alternative to exenteration for locally advanced vulvovaginal cancer. II. Results, complications, and dosimetric and surgical considerations. Am J Clin Oncol 1987; 10: 171-181

37 Scheistroen $M$, Trope C. Combined bleomycin and irradiation in preoperative treatment of advanced squamous cell carcinoma of the vulva. Acta Oncol 1993; 32: 657-661

38 Eifel PJ, Morris M, Burke TW et al. Prolonged continuous infusion cisplatin and 5-fluorouracil with radiation for locally advanced carcinoma of the vulva. Gynecol Oncol 1995; 59: 51-56

39 Landoni F, Maneo A, Zanetta G et al. Concurrent preoperative chemotherapy with 5-fluorouracil and mitomycin $\mathrm{C}$ and radiotherapy (FUMIR) followed by limited surgery in locally advanced and recurrent vulvar carcinoma. Gynecol Oncol 1996; 61: 321-327

40 Moore DH, Thomas GM, Montana GS et al. Preoperative chemoradiation for advanced vulvar cancer: a phase II study of the Gynecologic Oncology Group. Int J Radiat Oncol Biol Phys 1998; 42: 79-85

41 Montana GS, Thomas GM, Moore DH et al. Preoperative chemo-radiation for carcinoma of the vulva with N2/N3 nodes: a gynecologic oncology group study. Int J Radiat Oncol Biol Phys 2000; 48: 1007-1013

42 Gerszten K, Selvaraj RN, Kelley J et al. Preoperative chemoradiation for locally advanced carcinoma of the vulva. Gynecol Oncol 2005; 99: 640644

43 Shylasree TS, Bryant A, Howells RE. Chemoradiation for advanced primary vulval cancer. Cochrane Database Syst Rev 2011; 4: CD003752

44 Homesley HD, Bundy BN, Sedlis A et al. Radiation therapy versus pelvic node resection for carcinoma of the vulva with positive groin nodes. Obstet Gynecol 1986; 68: 733-740

45 Barnes EA, Thomas $G$. Integrating radiation into the management of vulvar cancer. Semin Radiat Oncol 2006; 16: 168-176 